Guest Editorial, part of a Special Feature on Understanding the Vulnerability and Sustainability of Urban Social-Ecological Systems in the Tropics: Perspectives from the City of San Juan

\title{
Tropical cities are diverse and deserve more social-ecological attention
}

\author{
Ariel E. Lugo $^{1}$
}

When I visit cities in the tropics, I am always fascinated by their diversity, not only their cultural diversity but also the diversity of vegetation and cityscapes. While New York City has a constructed Central Park, Belém in Brazil has the Jardim Botânico da Amazonia Bosque Rodrigues Alves, a 16-ha patch of natural lowland rain forest. My hometown of San Juan has scattered natural patches of novel moist forests with unique combinations of native and introduced tree species. From high-rise downtown buildings in Kingston, Jamaica; San Juan, Puerto Rico; or Santo Domingo in the Dominican Republic, one can appreciate the diverse tree cover of Caribbean cities. In these cities as well as others such as Georgetown, Guyana; Caracas, Venezuela; BasseTerre, Guadeloupe; or Roseau, Dominica, human activity takes place at a torrid clip and provides multiple rewards to visiting tourists and those who enjoy watching people in action. However, the combined effects of tropical conditions and overuse usually strain the gray infrastructure of tropical cities. It is common to see declining neighborhoods, crowded conditions, and eutrophic waters, all of which can endanger human health and create social and ecological vulnerabilities for tropical cities. Both social and ecological systems of cities adapt to the rapidly changing conditions within tropical cities and in the process generate novelty and functioning that somehow sustain the cities temporally and spatially.

As happens with tropical forests, the study of tropical cities from a social-ecological perspective lags behind the study of temperate cities, in part because scientific activity in the tropics is not supported at the same levels as it is in temperate countries. Scientific activity in tropical countries remains fragmented and isolated such that the studies that do take place are not generally known to the global scientific community. Moreover, addressing city functioning holistically is difficult and presents a challenge to both social and ecological sciences that must somehow collaborate through integrated research studies if they are to contribute to the general understanding of cities. It is not helpful that ecological sciences in the tropics have traditionally emphasized mature tropical forests while eyeing cities as places that hinder conservation and thus do not merit ecological research (Lugo 2010).
This special feature contains the results of a group of social and ecological scientists that joined forces in taking a social-ecological approach to the study of an urban watershed in San Juan, Puerto Rico (Lugo et al. 2011). Although San Juan is the oldest city under U.S. jurisdiction, up until now social and ecological scientists had not teamed up to study city functioning and vulnerabilities in the context of natural and anthropogenic disturbances. As individual articles in this feature illustrate, and summarized by MuñozErickson et al. (2014), the authors found numerous social and ecological surprises as well as reasons to suggest that tropical cities exhibit fundamental differences from temperate ones. We are now convinced that the interaction between green cover, people, and institutions in the tropics poses as great a challenge to those who study them. The bottom line is that scientific understanding of diverse tropical cities will require more dedicated scientific attention.

Responses to this article can be read online at: http://www.ecologyandsociety.org/issues/responses. $\mathrm{php} / 6618$

\section{Acknowledgments:}

This was done in collaboration with the University of Puerto Rico. I thank Mildred Alayón for her help with the manuscript.

\section{LITERATURE CITED}

Lugo, A. E. 2010. Let's not forget the biodiversity of the cities. Biotropica 42(5):576-577. http://dx.doi.org/10.1111/ j.1744-7429.2010.00673.x

Lugo, A. E., O. M. Ramos González, and C. Rodríguez Pedraza. 2011. The Río Piedras watershed and its surrounding environment. FS-980, U.S. Forest Service, International Institute of Tropical Forestry, Río Piedras, Puerto Rico.

Muñoz-Erickson, T. A., A. E. Lugo, and B. Quintero. 2014. Emerging synthesis themes from the study of social-ecological systems of a tropical city. Ecology and Society 19(3): 23. [online] URL: http://dx.doi.org/10.5751/ES-06385-190323 